\title{
Comparative analysis for quantification of Citrus Variegated Chlorosis in the field
}

\author{
Fabrício Packer Gonçalves ${ }^{1}$, Silvia Afonseca Lourenço ${ }^{4}$, Eduardo Sanches Stuchi², Bernhard \\ $\mathrm{Hau}^{3}$, Lilian Amorim* \\ ${ }^{1}$ USP/ESALQ - Programa de Pós-Graduação em Fitopatologia. \\ ${ }_{3}^{2}$ Estação Experimental de Citricultura de Bebedouro, C.P. 74 - 14700-000 - Bebedouro, SP - Brasil. \\ ${ }^{3}$ Hannover University/Inst. of Plant Diseases and Plant Protection, D-30419 Hannover Germany. \\ ${ }^{4}$ USP/ESALQ - Depto. de Fitopatologia e Nematologia, C.P. 9 - 13418-900 - Piracicaba, SP - Brasil. \\ *Corresponding author <liamorim@esalq.usp.br> \\ Edited by: Jorge Alberto Marques Rezende
}

\begin{abstract}
Citrus Variegated Chlorosis (CVC) caused by Xylella fastidiosa is one of the most important diseases for Brazilian citriculture. The CVC is a vascular disease with a long incubation period and symptoms similar to other disorders, and this factors difficult the CVC quantification in the field. Two methods of CVC assessment were compared in this study. The first method was based on a descriptive rating scale with four ratings, commonly used for the disease quantification. The second one was based on the incidence of symptomatic branches. The quantification of CVC through these two methods was carried out in a 10-year-old 'Natal' sweet orange orchard. The descriptive scale considered the symptoms of the entire plant. The disease incidence was evaluated in 36 branches in each plant. The assessments were conducted by three raters in 144 plants in July 2006 and July 2007 as well as in March and November 2008. The descriptive scale did not allow an accurate assessment and resulted in a moderate strength of agreement among the raters. On the other hand, the incidence quantification of CVC through the symptomatic branches showed high repeatability among the raters. We suggest the use of incidence of symptomatic branches as variable for CVC quantification.

Keywords: Phytopathometry, ordinal data, disease assessment
\end{abstract}

\section{Introduction}

Citrus Variegated Chlorosis (CVC), caused by the bacterium Xylella fastidiosa Wells et al., has been present in Brazil for at least 20 years and the losses caused by the disease reach $\$ 120$ million dollar per year (Bové and Ayres, 2007). The control of the disease is based on the use of healthy nursery plants, chemical control of the insect vector and eradication or pruning of plants. The perennial habit of citrus plants plus some characteristics of CVC such as being a vascular disease, long incubation period (Bergamin Filho and Amorim, 2002) and symptoms similar to other disorders, are factors which difficult the CVC quantification in the field. However, the CVC quantification is based on descriptive rating scales, both in epidemiological studies (Ayres et al., 2001; Laranjeira and Pompeu Jr., 2002), as well as on the evaluation of resistant genotypes (Stuchi et al., 2004; Souza et al., 2006).

The major disadvantage of the use of descriptive scales in disease assessment is that the actual rating values used are arbitrary (Madden et al., 2007). In the scales, the difference between rating values is not interpretable, at least not in a quantitative sense (Shah and Madden, 2004). As a consequence, the use of descriptive scales makes more difficult the quantitative comparison of the disease between varieties and the establishment of a damage function. Disease incidence and severity are the most frequent variables for plant disease estimation. The incidence is usually adopted in the assessment of vascular diseases, such as CVC (Amorim, 1995). Thus, our objective was to compare two methods of CVC quantification: (i) a descriptive rating scale with four ratings and (ii) the incidence of symptomatic branches.

\section{Materials and Methods}

The quantification of CVC was carried out in an orchard planted in February 1999 located in Bebedouro, São Paulo State, Brazil (205' S; $\left.48^{\circ} 28^{\prime} \mathrm{W}\right)$. 'Natal' sweet orange scions (Citrus sinensis L. Osb.), grafted on 'Rangpur' lime rootstocks (Citrus limonia L. Osb.) were planted in a spacing of $6 \mathrm{~m} \times 4 \mathrm{~m}$ in an area of $13,824 \mathrm{~m}^{2}$. The experimental design was a randomized block arrangement, at a $3 \times 2$ factorial scheme, with the following treatments: no irrigation; irrigated with $50 \%$, and $100 \%$ of the evapotranspiration of the crop; combined with natural and artificial inoculation of $X$. fastidiosa. Thus, different levels of the disease were observed in each plot. The natural inoculation occurred through insect vectors of $X$. fastidiosa (Yamamoto et al., 2007). The artificial inoculation was carried out by grafting infected buds 10 months after planting. The efficiency of artificial inoculation was confirmed six months later using PCR with specific primers for $X$. fastidiosa (Pooler and Hartung 1995). Each plot was composed of 24 plants, six of which were evaluated. All plots were assessed.

The quantification of CVC intensity was conducted with two methods: (i) using a descriptive rating scale with four ratings, in which 0 represents plants without symptoms; 1 represents plants with at least one leaf up to a branch with symptoms; 2 represents plants with more than one branch up to $50 \%$ of the canopy with symptoms; and 3 represents 
plants with more than $50 \%$ of the canopy showing symptoms in leaves and fruit (Salva et al., 1995), and (ii) estimating the incidence of symptomatic branches, in which six branches randomly chosen were evaluated in the lower part of the plant, six in the upper part and six in the middle on two sides of the plant (between rows), totalizing 36 branches evaluated. The assessment consisted in presence or absence of symptoms in the first $20 \mathrm{~cm}$ of each branch. Disease assessments were carried out in July 2006, July 2007, March and November 2008. Each assessment was performed by three raters on 144 plants. Two raters (1 and 2) participated in all assessments. The rater 3 was not the same in each assessment.

The inter-raters repeatability for disease incidence was estimated by the coefficient of determination $\left(\mathrm{R}^{2}\right)$, obtained from regression among the raters (Nutter Jr et al., 1991). Furthermore, all data collected through quantification using the descriptive scale were confronted with data collected through the quantification of the incidence of branches with symptoms. To compare the inter-rater agreement of two raters using the descriptive scale (0 to 3), tables were created with the frequencies of the ratings of two raters like Table 1 for raters 1 and 2 . The percentage agreement was then calculated by dividing the sum of the diagonal of the matrix $(21+54$ $+137+139=351)$ by the total number of observations (576). In addition, the assessing agreement of two raters using the descriptive scale was determined by Cohen's unweighted kappa and the kappa with linear weighting (identical to absolute error weights) (Jakobson and Westergren, 2005).

\section{Results and Discussion}

Symptoms in plants were distributed in an irregular way. The upper part showed higher disease incidence than the lower part and the difference ranged from 57 to $88 \%$, depending on the treatment (data not shown). The descriptive rating scale with four ratings, frequently used in assessments of CVC (Ayres et al., 2001; Souza et al., 2006; Stuchi et al., 2004), was not adequate to quantify the disease. Different plants which received the same rating had very different incidences of branches with CVC (Figure 1). Plants with rating 0 (healthy plants) showed incidences of up to $50 \%$ of branches with CVC and plants with rating 1 showed incidences from 0 to $70 \%$ (Figure 1). Furthermore, plants with

Table 1 - A comparison of Citrus Variegated Chlorosis (CVC) assessment of raters 1 and 2 using the rating scale with ratings 0 to 3 .

\begin{tabular}{lccccc}
\hline \multirow{2}{*}{ Rater 1} & \multicolumn{5}{c}{ Rater 2} \\
\cline { 2 - 6 } & 0 & 1 & 2 & 3 & Total \\
\hline 0 & 21 & 15 & 3 & 0 & 39 \\
1 & 30 & 54 & 35 & 1 & 120 \\
2 & 9 & 36 & 137 & 21 & 203 \\
3 & 4 & 7 & 64 & 139 & 214 \\
\hline Total & 64 & 112 & 239 & 161 & 576 \\
\hline
\end{tabular}

rating 3 , the highest rating of the scale, showed incidences between 0 and $100 \%$ of branches with symptoms of CVC (Figure 1). Thus, using this scale, the raters overestimated and/or underestimated the quantity of the disease.

In $0.17 \%$ of the cases, the incidence of $0 \%$ of symptomatic branches was quantified in plants with rating 3 (Table 2). This contrast in assessment occurred in trees affected by other disorders that cause symptoms similar to the ones of $\mathrm{CVC}$, as zinc deficiency and severe attack of mealy bug. In these cases, the rating was badly attributed and the quantification using the scale caused an overestimation of the disease level.
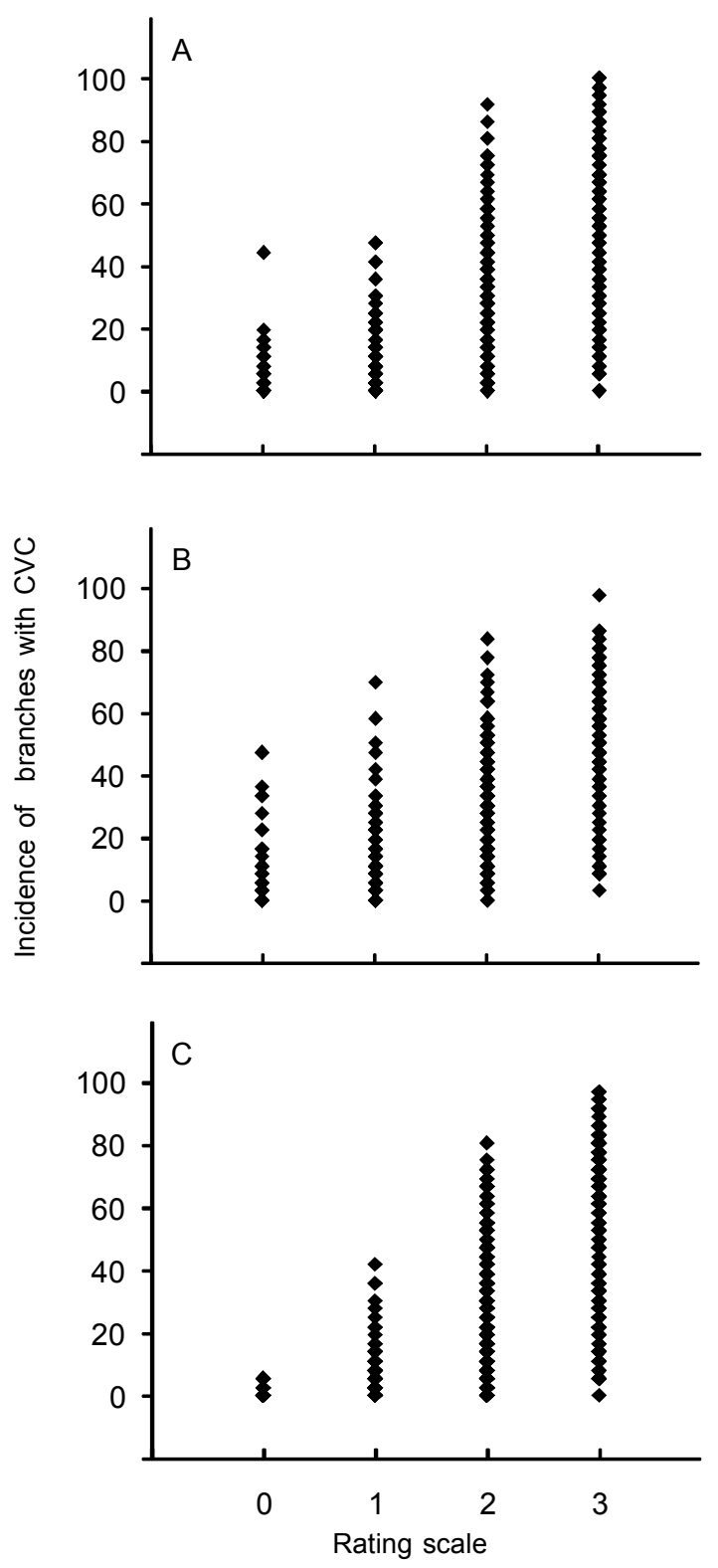

Figure 1 - Relationship between incidence (\%) of branches with symptoms of Citrus Variegated Chlorosis $(\mathrm{CVC})$ and rating scale for all treatments of rater 1 (A), rater 2 (B) and rater 3 (C) for all assessments from 2006 to 2008 . 
Table 2 - Percentage of branches with Citrus Variegated Chlorosis (CVC) symptoms attributed to plants that received ratings $0,1,2$ and 3 by the three raters.

\begin{tabular}{|c|c|c|c|}
\hline \multirow{2}{*}{ Branches with CVC symptoms (\%) } & \multicolumn{3}{|c|}{$\%$ of rating 0} \\
\hline & 1 & 2 & 3 \\
\hline $0-10$ & 69.2 & 76.6 & 100.0 \\
\hline $11-20$ & 28.2 & 10.9 & 0 \\
\hline $21-30$ & 0 & 4.7 & 0 \\
\hline $31-40$ & 0 & 4.7 & 0 \\
\hline $41-50$ & 2.6 & 3.1 & 0 \\
\hline$>50$ & 0 & 00 & 0 \\
\hline \multirow{2}{*}{ Branches with CVC symptoms (\%) } & \multicolumn{3}{|c|}{$\%$ of rating 1} \\
\hline & 1 & 2 & 3 \\
\hline $0-10$ & 46.7 & 45.5 & 64.4 \\
\hline $11-20$ & 30.8 & 28.6 & 22.0 \\
\hline $21-30$ & 13.3 & 17.0 & 6.8 \\
\hline $31-40$ & 4.2 & 4.5 & 5.1 \\
\hline $41-50$ & 5.0 & 1.8 & 1.7 \\
\hline$>50$ & 0 & 2.7 & 0 \\
\hline \multirow{2}{*}{ Branches with CVC symptoms (\%) } & \multicolumn{3}{|c|}{$\%$ of rating 2} \\
\hline & 1 & 2 & 3 \\
\hline $0-10$ & 14.3 & 15.9 & 18.4 \\
\hline $11-20$ & 18.7 & 22.6 & 20.7 \\
\hline $21-30$ & 15.8 & 16.3 & 13.9 \\
\hline $31-40$ & 23.6 & 18.8 & 19.4 \\
\hline $41-50$ & 9.4 & 11.3 & 10.9 \\
\hline$>50$ & 18.2 & 15.1 & 16.7 \\
\hline \multirow{2}{*}{ Branches with CVC symptoms (\%) } & \multicolumn{3}{|c|}{$\%$ of rating 3} \\
\hline & 1 & 2 & 3 \\
\hline $0-10$ & 5.6 & 5.6 & 3.6 \\
\hline $11-20$ & 11.7 & 8.7 & 6.6 \\
\hline $21-30$ & 8.4 & 3.7 & 8.7 \\
\hline $31-40$ & 10.3 & 7.5 & 10.2 \\
\hline $41-50$ & 7.0 & 14.9 & 5.1 \\
\hline$>50$ & 57.0 & 59.6 & 65.8 \\
\hline
\end{tabular}

The percentage agreement of raters 1 and 2 was $61 \%$. It was similar for the two other comparisons, $63 \%$ for raters 1 and 3 and $61 \%$ for raters 2 and 3. The unweighted kappa coefficients were 0.44 ( \pm 0.029$)$ (comparing raters 1 and 2 ), $0.45( \pm 0.030)$ (raters 1 and 3 ) and $0.42( \pm 0.030)$ (raters 2 and 3 ). These kappa values are within the range between 0.41 and 0.60 , which is considered as showing a moderate strength of agreement according to Landis and Koch (1977). When the linear weighting was applied, a method that is most appropriate for ordinally scaled data, the kappa coefficients increased to 0.57 ( \pm 0.024$)$ (comparing raters 1 and 2 ), $0.57( \pm 0.025)$ (raters 1 and 3 ) and 0.52 ( \pm 0.025) (raters 2 and 3). Nevertheless, these values also reflect only a moderate strength of agreement. The regression analysis carried out with data from the incidence of branches with symptoms resulted in $\mathrm{R}^{2}$ between 0.80 and $0.83(p<0.01)$ for all regressions (Figures 2A-C). The values of the slope of the regression lines were close to $1(1.01 \pm 0.02$ for raters 1 and 2 ; $0.90 \pm 0.01$ for raters 1 and 3; $0.80 \pm 0.01$ for raters 2 and 3) when the disease was quantified by the incidence method (Figure 2). These results show higher correlations between the raters using the incidence than the descriptive rating scale as a quantification method of the disease.

The quantification of diseases with descriptive scales cannot be analyzed with parametric methods of statistical analysis (Shah and Madden, 2004). According to the nonparametric method used in this study, better correlations between raters were achieved when the disease
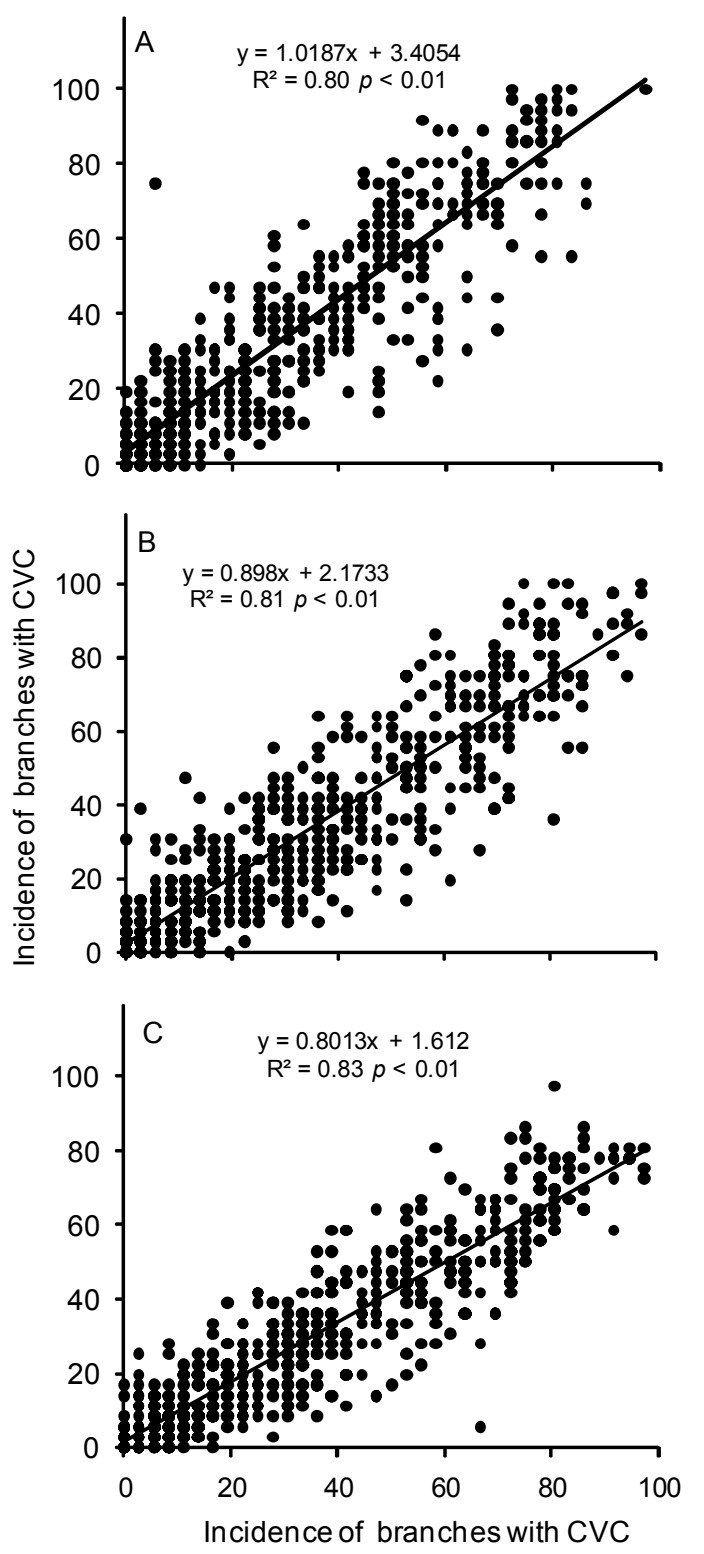

Figure 2 - Linear regression between raters 1-2 (A), 1-3 (B) and 23 (C) using the incidence parameter as method to quantify Citrus Variegated Chlorosis (CVC) in all assessments from 2006 to 2008. 
intensity was high. This fact is due to the 4 point categorical scale for CVC that has only 3 levels for disease assessment as value 0 means healthy plant. As a consequence levels 2 and 3 include most of the trees assessed (Table 1). However, there are successful cases for the use of descriptive scales in other pathosystems, for instance in the ornamental plant poinsettia (Euphorbia pulcherrima Wild) infected by Rbizoctonia solani Kühn (Krause et al., 2001) and tomato infected by Tomato mottle virus (Murphy et al., 2000).

Incidence observation takes more time than the descriptive scale. In this study, for example, disease assessments were made in approximately $210 \mathrm{~s}$ and $60 \mathrm{~s}$, respectively, for disease incidence and descriptive scale. This fact restrains the use of disease incidence assessments in regional surveys of CVC, such as those carried out by the Fund for Citrus Plant Protection (Fundecitrus) in Brazil, where thousands of plants are evaluated every year. However, the incidence ("all or nothing" disease) as a variable is not subjective (Bergamin Filho and Amorim, 1996), and allows precise assessments of disease by the raters or farmers. Thus, for the standardization of CVC quantification, the use of disease incidence as variable is suggested, at least for experimental purposes.

\section{Acknowledgements}

To The National Council for Scientific and Technological Development (CNPq) for financial support during the course of this research. This work is part of the doctoral thesis of the $1^{\text {st }}$ author, who received a fellowship from CNPq.

\section{References}

Amorim, L. 1995. Assessment of plant diseases. p. 647-671. In: Bergamin Filho, A.; Kimati, H.; Amorin, L., eds. Handbook of plant pathology. Agronômica Ceres, São Paulo, SP, Brazil. (in Portuguese).

Ayres, A.J.; Gimenes-Fernandes, N.; Barbosa, J.C. 2001. Intensity of the citrus variegated chlorosis in the state of São Paulo and South of Triângulo Mineiro. Summa Phytopathologica 27: 189197. (in Portuguese, with abstract in English).

Bergamin Filho, A.; Amorim, L. 2002. Diseases with a variable incubation period as a function of the host phenology. Fitopatologia Brasileira 27:561-565. (in Portuguese, with abstract in English).
Bergamin Filho, A.; Amorim, L. 1996. Diseases of tropical plants: epidemiology and economic control. Agronômica Ceres, São Paulo, SP, Brazil. (in Portuguese).

Bové, J.M.; Ayres, A.J. 2007. Etiology of three recent diseases of citrus in São Paulo State: Sudden Death, Variegated Chlorosis and Huanglongbing. IUBMB Life 59: 346-354.

Jakobson, U.; Westergren, A. 2005. Statistical methods for assessing agreement for ordinal data. Scandinavian Journal of Caring Sciences 19: 427-431.

Krause, M.S.; Madden, L.V.; Hoitink, H.A.J. 2001. Effect of potting mix microbial carrying capacity on biological control of Rhizoctonia damping-off of radish and Rhizoctonia crown and root rot of poinsettia. Phytopathology 91: 116-1123.

Landis, R.J.; Koch, G.G. 1977. The measurement of observer agreement for categorical data. Biometrics 33: 159-174.

Laranjeira, F.F.; Pompeu Jr, J. 2002. Perfomance of 15 cultivars of sweet oranges affected by Citrus Variegated Chlorosis. Laranja 23: 401-411. (in Portuguese, with abstract in English).

Madden, L.V.; Hughes, G.; Van Den Bosh, F. 2007. The Study of Plant Disease Epidemics. APS Press, St. Paul, MN, USA.

Murphy, J.F.; Zehnder, G.W.; Schuster, D.J.; Sikora, E.J.; Polston, J.E.; Kloepper, J.W. 2000. Plant growth-promoting rhizobacterial mediated protection in tomato against Tomato mottle virus. Plant Disease 84: 779-784.

Nutter Jr, F.W.; Teng, P.S.; Shokes, F.M. 1991. Disease assessment terms and concepts. Plant Disease 75: 1187-1188.

Pooler, M.R.; Hartung, J.S. 1995. Specific detection and identification of Xylella fastidiosa strains causing citrus variegated chlorosis. Current Microbiology 31: 377-381.

Salva, R.A.; Roberto, S.R.; Carlos, E.F. 1995. Surveys of CVC in the São Paulo State, Brazil. Laranja 16: 155-164. (in Portuguese, with abstract in English).

Shah, D.A.; Madden, L.V. 2004. Nonparametric analysis of ordinal data in designed factorial experiments. Phytopathology 94: 33-43.

Souza, P.S.; Goes, A.; Stuchi, E.S.; González, E.P.; Wickert, J.E.; Silva, S.R.; Donadio, L.C 2006. Reaction of oranges varieties and clones to Xylella fastidiosa. Revista Brasileira de Fruticultura 28: 144-147. (in Portuguese, with abstract in English).

Stuchi, E.S.; Donadio, L.C.; Sempionato, O.R.; Perecin, D. 2004. Yield and fruit quality of 'Pêra' sweet orange clone iac on 16 rootstocks in Bebedouro region, State of São Paulo, Brazil. Revista Brasileira de Fruticultura 26: 359-362. (in Portuguese, with abstract in English).

Yamamoto, P.T.; Felippe, M.R.; Caetano, A.C.; Sanches, A.L.; Lopes, J.R.S. 2007. First report of Fingeriana dubia Cavichioli transmitting Xylella fastidiosa to citrus. Fitopatologia Brasileira, 32: 266-2007.

Received September 23, 2010

Accepted February 16, 2011 